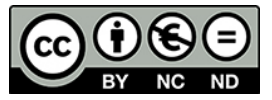

\title{
A Non-standard Society Is Getting New Clothes: Evidencing Knowledge Gaps with C-K Design Innovation Theory
}

\section{Dr. Patrick Corsi}

Gérant IKBM Sprl, Avenue Louise 317, 1050 Brussels, Belgium.

Associate researcher, Presence \& Innovation Lab, LAMPA (EA1427), Arts et Métiers ParisTech (ENSAM), Angers/Laval, France.

patrick.corsi@skynet.be

\section{Key-words}

Systems thinking, knowledge management, post-capitalist economy, C-K theory, intangible assets.

\section{Abstract}

Emergence of post-industrial societies is found on knowledge as a primary resource. The paper evidences changes from previous society's phases of functioning and shows ways for centering knowledge in post-industrial times. Concepts are reformulated with C-K design innovation Theory, fostering the way towards transdisciplinarity.

The case of generating co-working spaces illustrates knowledge absorption and networkbased intensities, opening avenues for altering working paradigms that shift collaborative experiences. This is core to the advent of fully-fledged Knowledge societies (KS) where ternary models develop, socio-economic molds spiral up qualitative growth, thus departing from past dual fragmentations.

\section{SOME EVOLUTIONARY DRIVERS OF MODERN SOCIETY}

\section{Where we come from and might go}

Society inherits from the Industrial Revolution whereby human, then machine force underpinned work. Its knowledge legacy has names: planning, control, optimization... Contrastively, social/individual/environmental dimensions underwent limited change despite technological accelerations.

When digital networks appeared towards the end of the $20^{\text {th }}$ century, immaterial items soon moved, escaping the permanence of control, storage, and ownership. Dominant designs projected piloting frameworks based on decision sciences. By leaving behind e.g. linearity and planning concepts, and embracing those of interaction, interdependence, complexity, and convergence, they began to dwindle; new paradigms emerged transcending old views about working, playing, and living. 


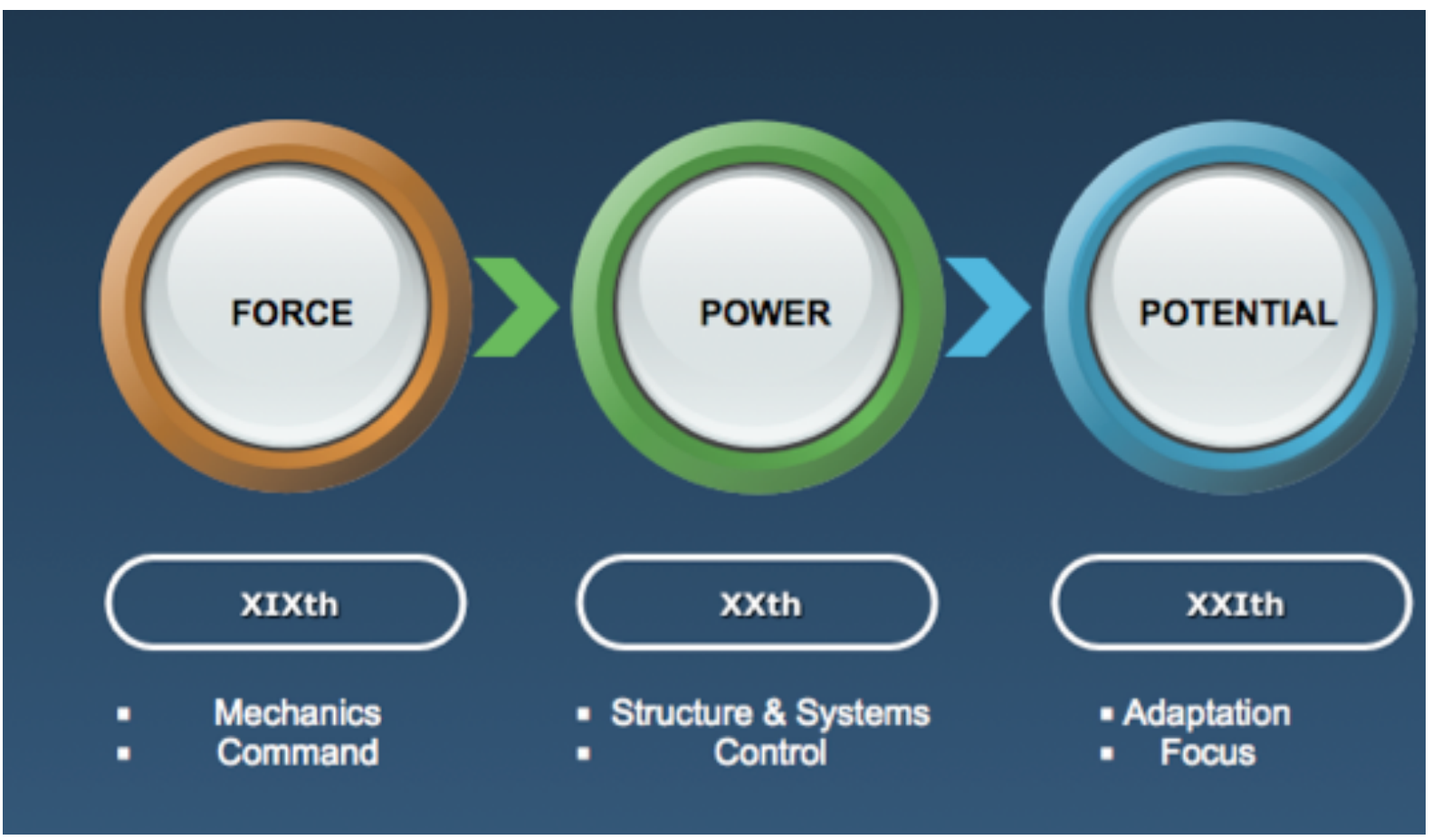

Figure 1. As civilization moves on, it transforms its own drivers.

The earlier years of the $21^{\text {th }}$ century evidenced an emerging divide: to stay riveted on control and perfect optimization or, in blatant but liberating moves, adapt to new conditions: those of dynamic networks where members co-evolve, seek equilibrium and constant adaptation. There, Knowledge is argued as core ingredient.

\section{KS: a phase only of mankind evolution?}

\section{A KS has two sides}

To our retrospective astonishment, in a most singular move, the European Commission early published a white paper (EC, 1994) alerting on the "big shift" significance and provided the rationale underpinning the upcoming KS paradigm. Even more amazingly, the heads of member states backed it officially. How far have we gone today?

When knowledge deeply underpins socio-economic operations, what are the generic laws regulating society, with what benefits and what challenges? What are the drivers of a "post-capitalist society"? -a term coined by Peter Drucker: "That knowledge has become the resource rather than a resource, is what makes our society "post-capitalist." This fact changes - how fundamentally - the structure of society. It creates new social and economic dynamics, it creates new politics." (Drucker, 93).

What Drucker did not however explicitly envision (Luyckx-Ghisi, 12) are:

- Intangible assets. Dematerializing content and methods leads to accelerating society's evolution.

- Win-win strategies, open business models They unfold seemingly unbounded dynamics (augmentative" strategies).

- Machine being subordinated to man. intuitive interfaces enable users (à-laiPod/iPad...). 
In positive scenarios, post-capitalist logics powered by Knowledge represent a quantum shift from a command\&control type of society towards human-centered logic. Nonpositive ones involve manipulating human minds, representing another evolved form of command\&control. Core issues are: the governance of $\mathrm{KS}$, how to organize the value spaces generated.

\section{Where talent becomes essential}

Knowledge underpins talent when used with know-how. Talent knows no political/national/regional boundary as the direct evolving outcome of a free and conscious use of capacities and skills. Knowledge is transformed in new capital: Talent. Freedom in making knowledge flow grows qualitative yields that transcend the usual quantitative outputs traditionally accounted for in economics statistics. No clear-cut indicator (besides those dealing with workforce attributes) seems to track these dynamics.

Talent however does not contradict traditional indicators: access to talent (easy, comparative; flexible) is prerequisite for all innovating industries. Lack of talent fast dries up research originality and variety, bounding its quality and value. In striving KS, ever more than in previous epochs, it is talent (not knowledge) that represents the harpoons and hatchets of business models for commerce, industry and economy.

Why most economists still lock models in past visions of what represents value, wealth, and productive yields? The traditional indicator of an industrial society production is the GDP/GNP. Resources were mineral ore and natures' vegetal and animal productions. Society was dominated by Information (which is based on Data). The more voluminous Information became, the more dependent Society became from it: a society generated by Information. Re-generating it was impossible until Internet began to depolarize crystallized hierarchical structures and re-polarize them as flows.

Knowledge has become the primary resource (think of the successful strategies of countries having no mineral resources. When immaterial tools are over abundant, competition may top: what would you do to differentiate? Talent is a direct answer; unfortunately, the kind of teaching formally available around doesn't answer and misses the ontological education's value point "guiding beyond". Foster Talent Network Product at core of a striving society, increasingly replace GNP-based measures and statistics. TNP is relative to ecosystems (professional/industrial networks) and their indicators.

Command and control models can't cope: goals and objectives aren't sealed for ever, they co-evolve with the systems' agents, are coherent with the whole. Models are no longer top-down and/or bottom up: they become generative. Planning becomes a thing of the past as changes overtake the plan ${ }^{1}$.

An interesting question is "how to structure a society based on Talent?" Answer: the network probably structures it. "How to govern it?" Probably through "harmony rules". The only way to sustain processes therein is to balance flows. Could this become new Politics Science?

The notion of competing may become replaced by emulating as becoming obsolete in networks attitudes. The incidence on education becomes profound.

\footnotetext{
${ }^{1}$ Planning as a thing of the past: conquer by dividing (in time and space), and securing positions. It repels dynamics, i.e. waits for balancing forces from the ecosystems to take all over.
} 


\section{PART I - “RULES” OF A KNOWLEDGE-BASED ECONOMY}

\section{Capability and Future}

Talent expresses capability. A capability is given in the present and sourced from the past. Stretching it into future calls for "resilience", a type of energy bound to erosion, dissipation and entropy iff not put into use. Nurturing and measuring capacities as precious assets build sustainability.

Competence uses capacities/capabilities while anchoring on Present. It represents the ability to move/alter things (innovation as the art of altering the identity of objects) as it regenerates products, processes, services, organizations. Oppose it not to incompetence but to the position of a still Observer detached from situations.

Values that emerge are set in Present, not future. Scaling values expresses the intensities attached to value sets, which, in a KS, materialize the focus that society recognizes. Scaling down to organizations/individuals points to local meanings and priorities. When value focus is centered on capabilities, competence eventually results.

\section{On discerning Knowledge impact}

What's the genuine difference between Data, Information and Knowledge?

- Data: a result of some measure in time, space or else: a date, a temperature, a fact.

- Information: descriptions attached to a collection of data. Huge sets of information stored in gigantic repositories (information vaults) by means of descriptors manipulate data.

- Knowledge: reasoning about information. Note that information descriptors may be insufficient, not adapted, erroneous, hard to measure, etc.

A more comprehensive answer comes when plunging knowledge in a wider frame of reference (Fig. 3).

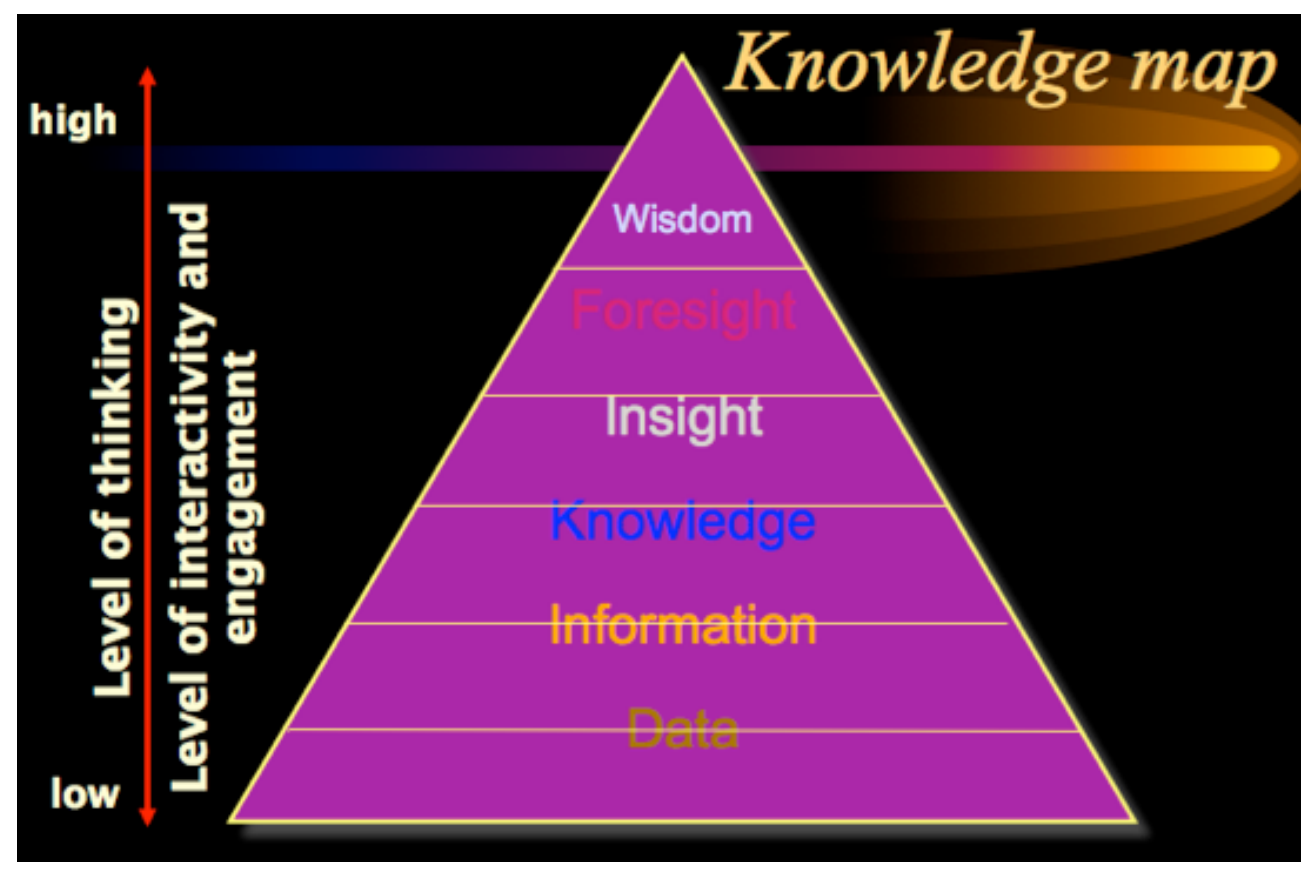

Figure 3. Mapping knowledge: Knowledge is but another layer in the evolution of society, acting as a working medium towards yet other openings. 
What is to be found or activated beyond knowledge? Table 1 analytically compares data, information, knowledge and intuition.

\begin{tabular}{|c|c|c|c|c|}
\hline & Data & Information & Knowledge & Intuition \\
\hline What it is & $\begin{array}{l}\text { Factual and } \\
\text { measurable } \\
\text { chunks (sets, } \\
\text { series...) }\end{array}$ & $\begin{array}{l}\text { Aggregated, } \\
\text { synthetized data }\end{array}$ & $\begin{array}{l}\text { Reasoned } \\
\text { information }\end{array}$ & $\begin{array}{l}\text { A-temporal \& } \\
\text { a-spatial }\end{array}$ \\
\hline Nature & Quantitative & $\begin{array}{l}\text { Both } \\
\text { quantitative and } \\
\text { qualitative }\end{array}$ & $\begin{array}{l}\text { Essentially } \\
\text { qualitative }\end{array}$ & Symbiotic \\
\hline $\begin{array}{l}\text { Governed by } \\
\text { laws of }\end{array}$ & $\begin{array}{l}\text { Statistics (what } \\
\text { about implicit } \\
\text { hypothesis?) }\end{array}$ & Data bases & $\begin{array}{l}\text { Knowledge } \\
\text { bases }\end{array}$ & $\begin{array}{l}\text { Quantum } \\
\text { physics, energy }\end{array}$ \\
\hline $\begin{array}{l}\text { Lowest } \\
\text { evolved form } \\
\text { structure }\end{array}$ & $\begin{array}{l}\text { Numbers, data } \\
\text { sets }\end{array}$ & $\begin{array}{l}\text { Categories } \\
\text { (catalogues...), } \\
\text { random lists }\end{array}$ & Coherent lists & $\begin{array}{l}\text { Hunches, inner } \\
\text { feelings, after } \\
\text { thoughts } \\
\text { (evanescent) }\end{array}$ \\
\hline $\begin{array}{l}\text { Intermediary } \\
\text { form structure } \\
\text { of evolution }\end{array}$ & $\begin{array}{l}\text { Aggregation of } \\
\text { data sets (cf. } \\
\text { axiomatics) }\end{array}$ & $\begin{array}{l}\text { Accounts, } \\
\text { reports, analysis }\end{array}$ & Storytelling & $\begin{array}{l}\text { Inner vision } \\
\text { (once) }\end{array}$ \\
\hline $\begin{array}{l}\text { Most evolved } \\
\text { form structure }\end{array}$ & $\begin{array}{l}\text { Temporal } \\
\text { series, patterns } \\
\text { of becoming, } \\
\text { weak signals }\end{array}$ & $\begin{array}{l}\text { Demonstrations, } \\
\text { analytics }\end{array}$ & $\begin{array}{l}\text { Synthetic } \\
\text { proofs }\end{array}$ & $\begin{array}{l}\text { Inner guidance } \\
\text { (continuous) }\end{array}$ \\
\hline Value & Instant, fixed & $\begin{array}{l}\text { Time-cycles } \\
\text { (bound to } \\
\text { obsolescence) }\end{array}$ & $\begin{array}{l}\text { Use (if not } \\
\text { used, } \\
\text { deteriorates) }\end{array}$ & Transcendental \\
\hline Access & $\begin{array}{l}\text { Need } \\
\text { measurement } \\
\text { device or } \\
\text { system }\end{array}$ & Reader & $\begin{array}{l}\text { Tutor } \\
\text { (repetition), } \\
\text { teacher } \\
\text { (contents, } \\
\text { techniques), } \\
\text { educator } \\
\text { (concepts, } \\
\text { methods) }\end{array}$ & $\begin{array}{l}\text { Inward look } \\
\text { (the first } \\
\text { reversal } \\
\text { moment in } \\
\text { evolution) }\end{array}$ \\
\hline $\begin{array}{l}\text { What it } \\
\text { enables }\end{array}$ & $\begin{array}{l}\text { Passive } \\
\text { consciousness }\end{array}$ & $\begin{array}{l}\text { Timely } \\
\text { reactivity }\end{array}$ & $\begin{array}{l}\text { Regulated } \\
\text { anticipation }\end{array}$ & $\begin{array}{l}\text { Vision, } \\
\text { "prospective" }\end{array}$ \\
\hline $\begin{array}{l}\text { It's most } \\
\text { critical or } \\
\text { weakest point }\end{array}$ & Observation & $\begin{array}{l}\text { Accountability, } \\
\text { rejection of over } \\
\text { information (say } \\
\text { no) }\end{array}$ & $\begin{array}{l}\text { Putting to } \\
\text { question, } \\
\text { dogmatic }\end{array}$ & Transferability \\
\hline $\begin{array}{l}\text { What it can't } \\
\text { do (the limits } \\
\text { to it) }\end{array}$ & Instruction & Intelligence & Wisdom & Action \\
\hline $\begin{array}{l}\text { How to } \\
\text { dissolve or } \\
\text { neutralize }\end{array}$ & $\begin{array}{l}\text { Change } \\
\text { parameter or } \\
\text { measure } \\
\text { method }\end{array}$ & $\begin{array}{l}\text { Grant right to } \\
\text { oblivion } \\
\text { (forgettable } \\
\text { information) }\end{array}$ & $\begin{array}{l}\text { Grant right to } \\
\text { defixation (shift } \\
\text { "assembly } \\
\text { point") }\end{array}$ & Dream \\
\hline
\end{tabular}


Table 1. An analytical positioning of Knowledge among other informational structures.

\section{Separaring knowledge from "imaginary worlds": the new "steam engine"}

Knowledge being propelled at the forefront of society's activity is only "activable" as operated in the current time-space of an ecosystem. We should distinguish the mechanistic principle that acts on Knowledge, (as e.g. steam acts in the boiler to produce pressure, in turns moving parts).

By now, society has developed an extraordinary corpus of knowledge: knowledge focus may become a fixation, a limiting evolutionary factor. Paradoxically, while knowledge avoidance seems out of scope, evolution may require departing form it. But how? We envision that the conceptual $\mathrm{C}-\mathrm{K}$ design machine ${ }^{2}$ may be poised to propel another revolution: an engine for fresh knowledge-based creativity.

Knowledge is formed by all that is known and that is known to be not known. Which includes theories, facts, sciences laws and the doctrines elaborated by mankind. Also experience, methods, and processes and associated know-how, successes and failures. False knowledge, known holes in knowledge are knowledge. The whole sum forms the $\mathbf{K}$ space, which is structured in knowledge pockets that may be disconnected. $\mathbf{K}$ space structure is therefore archipelagic.

An ontological question: What is dual to Knowledge that would help departing from it? Not meta-knowledge, as this is also knowledge. C-K theory introduces the dualism:

\section{Concepts-Knowledge}

A fundamental divide for KS. By Concepts, are meant propositions neither true nor false, that you can't prove anything about, just conjecture. Philosophically, a sort of knowledge negation. Our mind experiences difficulty in accepting that something is non-knowledge. Zen masters instruct that key to radical evolution lies in the art of transcending contradictions. In Western culture, oxymorons are well-known (ex. a bitter sweet sauce, a virtual reality, a working holiday, a dark light...). Oxymoronic expressions open a fantasy space that contains... nothing! And this emptiness is the spark of creative cycles. By accepting to start from empty spaces is an act of transcending humility found with greatest innovators and artists.

(Hatchuel \& Weil, 2007) found the way thanks to post-modern mathematics. A concept is formally defined as an undecidable proposition. Concepts are unavoidably expressed with words and phrases, which evidences the $\boldsymbol{K}$-relativity concepts, probably our ultimate boundary as human beings reasoning about reasoning. Formally, a concept can be expressed as an object X with K-relative properties P(X). Mathematically:

$$
\exists \mathrm{X}, \mathrm{P}(\mathrm{X})
$$

\footnotetext{
${ }^{2} \mathrm{C}-\mathrm{K}$ theory was invented by Armand Hatchuel in 1996 and avoids two traditional design misleading views: a) reasoning within a stabilized set of functions; and b) interpreting creativity in design as an uncontrollable process of idea generation. This paper does not detail the fundamentals of the theory (pls. see references).
} 
The chief aim of the $\mathbf{C}$ space is to avoid a deadlock on the $\mathbf{K}$ space as this would qualitatively restrict evolution to e.g. R\&D: the entire world would become a torment of problem-solving situations with optimization as our sole progress!

Let's now analyze deeper the two spaces obtained.

We accordingly hold the K-C separation as as ontologically important as the well-known paradigmatic architectural divide brought by John Von Neumann for stored-program computers in 1945 (Von Neumann, 45):

\section{Program $\leftarrow \rightarrow$ Data (being stored together in memory)}

Where a program is a sequence of mechanical instructions operating on data. Here, $\mathrm{K}$ and $\mathrm{C}$ interact co-operatively; which represents another quantum step in design capacity (thus transcending problem-solving) and prefigures new types of actions and possibilities for society in the future.

In the same vein as a Turing machine can be considered as a model of a general purpose computer (i.e. for code generation), an "Hatchuel machine" ${ }^{3}$ can be justifiably proposed as a model of generic purpose innovative design, appropriate for concept generation.

As concepts cannot be understood at first (often seeming crazy because out of habitudinal, recognizable contexts), the issue lies in formulating them practically: how to design a suitable $C_{\text {raw }}$ as a $K$-disjunctive concept? "Suitability" means maximizing expansibility:

$$
\mathrm{C}_{\text {raw }} \text { is an } \mathrm{Y}, \mathrm{Y} \in \mathbf{C} \text {, and satisfies } \mathrm{RP}
$$

Where RP is an empirical set of five properties that we evidenced in previous experiments (Corsi, 2013-13) for formulating a suitable $\mathrm{C}_{\text {raw }}$ concept (cf. Tables 2).

\section{RP: Five useful Root Properties for formulating suitable $\mathbf{C}_{\text {raw }}$}

1. Tension: use pairs of opposites, bring together elements that are spread far apart or found in extreme positions : e.g. by forming an oxymoron or by introducing dissonance, or with the emergence of new dissonant harmony. NB: property chiefly helps defixing from well-received consonant harmonies.

2. Focus Shift: use metaphors, analogies, or any comparison including poetic ones. NB: property helps communicability for collaboration, combats domainbased fixations (those of typical experts).

3. Variability: formulate in even more provocative forms. NB: property supports cognitive debiaising.

4. Genericity: make it as generic as possible (not general: this would damage specificity!). NB: property enhances expansibility.

5. Greying: introduce (doses of) noise by e.g. adding extraneous attributes (one by one). Attributes shift focus, get a new angle of view (hence can defix). NB: property eases our creaming and kneading the somewhat intractable expressions.

We adjoin five empirical rules for assessing the a priori value of a $C_{\text {raw }}$ :

\section{Rules of thumb for ex-ante $C_{\text {raw }}$ evaluation}

\footnotetext{
${ }^{3} \mathrm{~K}$ and $\mathrm{C}$ spaces, plus the four operators $\mathrm{K} \rightarrow \mathrm{C}$ (disjunctions), $\mathrm{C} \rightarrow \mathrm{C}$ (expansions), $\mathrm{C} \rightarrow \mathrm{K}$ (conjunctions), and $\mathrm{K} \rightarrow \mathrm{K}$ (computations). A unified theory of design, quite an awesome augmentation from the von Neumann model.
} 
1. "Radicality": sensibly evaluate degree of commonality, genericity, universality. NB. Helps assessing how root is the root.

2. Breakability: what are the prior factors, parameters and conditions that lied just before it been formulated? NB. Helps verifying whether any conceptual jump happens.

3. Variability: contextualize cross-domains, sectors, usages... Tip: name the hosting context first and project on that hyperplane. NB: May help assessing genericity.

4. Concision: no unnecessary or futile word. NB: Ensures generality. Hints: avoid language first, stick to making phrases from keywords only.

5. Sensoriality: can the five senses approach it? (Everything begins from senses).

Tables 2. How to design root concepts that radically disjoin from available knowledge?

In the end, a $\mathrm{C}_{\text {raw }}$ should look pretty strange mentally: an unbalanced and unrealistic conceptualization often looking crazed and delirious. Yet, having more than one is important: $\mathrm{C}_{\text {raw }}$ variations likely lead the designer towards diverging $\mathrm{C}-\mathrm{K}$ paths.

Learning to use a new language detached technology yet able to reason upon it restructures the thinking. Not content with manipulating information, we recreate it. Let's now apply the above conceptualizations to the case of co-working spaces, a transformational epitome of Knowledge-based society.

\section{PART II - CO-WORKING SPACES (CWS): TEMPLATES FOR KNOWLEDGE-BASED SOCIETIES}

\section{Why co-working as a subject matter?}

A working space instantiates the way work is seen to be accomplished within organizations. Since the advent of Internet-based networks, the social activity called networking gained enlarged definitions where communication gets augmented: a capacity to co-operate and collaborate with ever more participants remotely in ever increasing sizes of ecosystems. System feedback thinking returns local impacts: local coworkers reinterpret their roles, relations, and dynamics locally to the measure of the larger environment in which they dwell and act. The environment is co-substantial to the individual, both co-evolve by gaining implicit knowledge from immanent context and by focusing on specific locally-added values with a view to increase their global performance.

Working space are no longer spaces where people merely work! They've become spatiotemporal resources where agents interact within ever changing modalities. This is what we call 2.0 CWS. Issues are:

1. How to evolve from recent co-working models emerging everywhere recently?

2. How to design new 2.0 varieties that creatively evolve and differentiate from what already exists; with which features?

\section{Management principles for CWS}

Units of operation in Knowledge societies are "places" where people can co-operate (Fig. 4). Organized patterns of work express behaviors that arise from interactions between people. Social networks reveal emerging patterns almost independently from locality and 
time factors. How we think about people working together beyond is our subject matter when evolving co-working.

CWS
Working spaces for common use; can be used as à-la-carte offices
by any knowledge worker

Figure 4. A 1.0 definition for a co-working space.

Does a CWS operate with classical management values? Likely not so as collaborative intensity preempts top-down assignments and rules: management isn't the fact of assigned individuals but the co-appreciated mobilization of which activities could/should be done, how, anytime. Values first operate a CWS, not rules or models. A priori submission of co-working activities to business plans is very reductionist. CWS activity is chiefly bound to the feelings, desires, motivations of those who co-inhabit a co-activity place.

\section{Evolving classical views of CWS}

Advancing CWS to 2.0 status is seeking quantum leap from current co-working practices by ideating novel co-working models:

- Co-working practice gets augmented by creating two vaults types: common and transferable Knowledge Vaults KV referencing past and present, plus local and remote experiences; Concepts Vaults $\mathrm{CV}$ that taps on the $\mathrm{KV}$ and continuously expands them based on participants' creativity.

- As CWS values represent a strategic backbone, those boasted by 2.0 CWS extend the classical list (collaboration, alliance, partnership, cooperation, association, teamwork, union, combined effort) towards more openness (partaking, allocating, distributing, receptiveness, tolerance to others' deficiencies and palliating them, broadmindedness...).

As KS will explore new collaborative work and control modalities by inheriting from project management legacies stemming for the Industrial Revolution, we should care for transition phases whereby people may not collaborate easily, being bound to: intellectual protection behaviors; classical project management techniques; disciplinary or branches views (e.g. engineering, marketing, finances, manufacturing...). The notion of knowledge worker was introduced by Peter Drucker in... 1952. Knowledge-based approaches can't be stopped as society knows that innovation is favored when experimentation is fueled by new learning ways through co-working.

\section{CWS versions reflect core generational values}

\section{Root generation}

This is the notion of dedicated offices exemplified by large rooms permanently inhabited by responsible persons who e.g. mays occasionally get visitors (Fig. 5). 


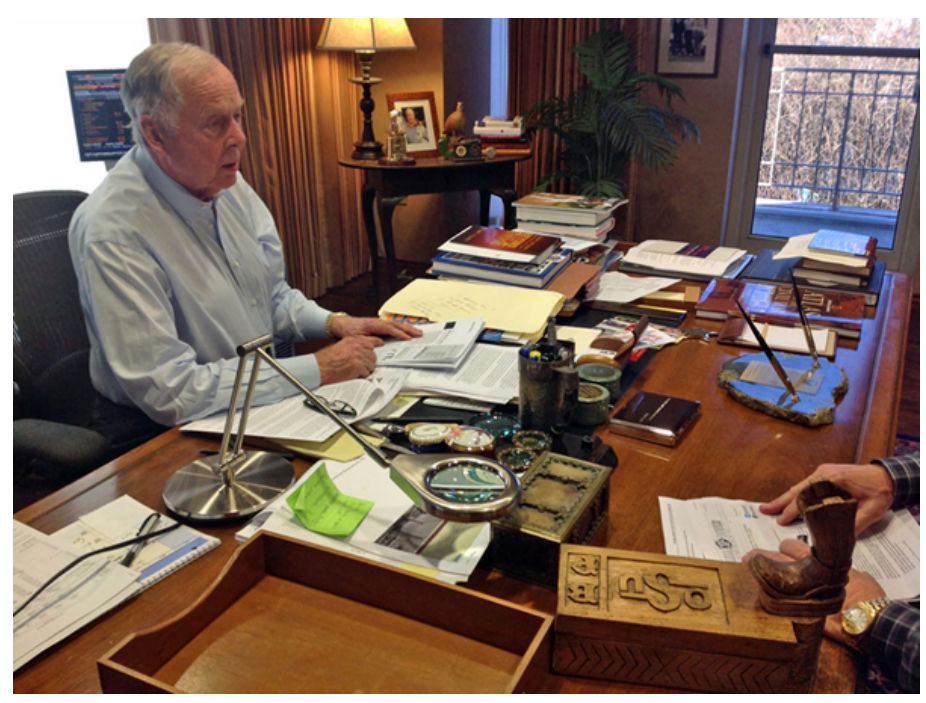

Figure 5. A view of T. Boone Pickens' working space, typical of the $20^{\text {th }}$ century. He was the founder, chairman and CEO at BP Capital and TBP Investments Management ${ }^{4}$.

\section{First generation (1.0)}

CWS traditionally include open spaces and closed areas for sharing work situations among people who may (or not) know each other. By fostering attitudes of openness and sharing, they intentionally support and vitalize the creativity of those present. Numerous formulas have been tried (in larger cities; estimated to grow at $300+\%$ pa depending on country).

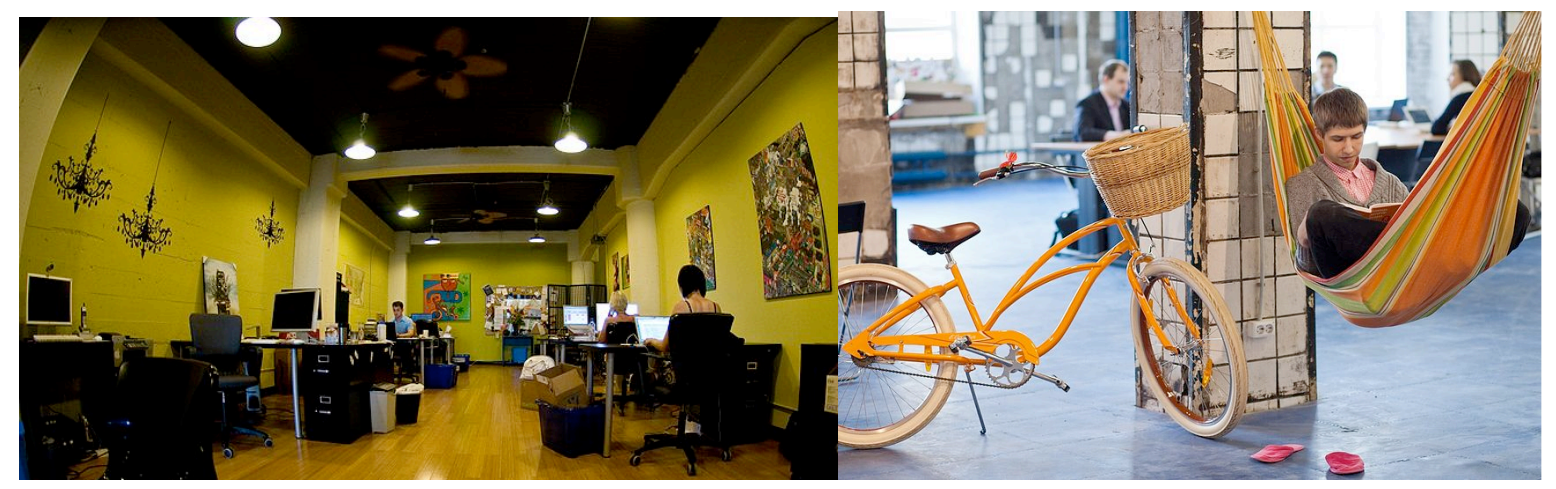

Figure 6. Typical $1^{\text {st }}$-gen CWS: in San Francisco (structured, organized); the Zonaspace (casual, creative atmosphere) in Saint-Petersburg.

Yet, these spaces have rules that separate, if not isolate, them from "mainstream spaces": "normal" work areas, as offices, cubicles, meeting rooms, hotel-based facilities...

First, they are often subject to reservation policy; alternatively co-workers are allotted an open space and observe implicit policies. Today CWS status is probably a form factor for

\footnotetext{
${ }^{4}$ Extracted from Paul Hobcraft: Where I Work: Three Decades of Deals at One Desk / Where I Work: Surrounded By People (and Swimming in Tea), LinkedIn, January 22, 2013: "Having colleagues nearby - whether at the beach or in a crypt - means the ideas are always flowing."
} 
doing work requiring few resources: energy supply, comfortable physical accommodation plus people whose implicit agreement leads to respect implicit conditions:

- given physical settings preempting custom needs,

- allocated time can't be projected freely.

Second, they concurrently accommodate those joining for short periods of time (attending a conference) and those hosting their main office by allocating differentiated areas. Third, they resist customization with respect to specific needs. Not speaking of privacy and confidentiality policies and issues, which may likely be left to the visitors' appreciation. 1.0 CWS remain rather loose areas ready for hosting people space and time. We argue this is a temporary view only.

\section{CWS 1.0}

Mission: To make a working real estate a priori available anytime for visitors Contingencies: Space and equipment usually not dynamically customizable wrt to usage intensity and type, public types... Privacy and confidentiality not easily addressable...

Figure 7. Some salient principles of a co-working space of the first generation.

\section{On next generations}

Future CWS will regenerate whole work environments from and today's seed embodiments. CWS shouldn't be seen as singular zones for rare people over exceptional time durations but rather as rich future working modes: original, variable, valuable and robust.

Early observations give credit to such view: mobility has grown ubiquitous among working populations with offices much on-the-go; remote ties between various physical settings pop up, grow and fade unceasingly; the cost of renting and furnishing working estates in large cities raises to heights. When Starbucks opened US in-shops WiFi offerings a decade ago - an Internet-connected space on a table for the price of a coffee cup or a monthly rate membership - they opened up one new market: an own pop-up mobile office at every city street corner. Spaces with more coherent, functional and evolutionary functions have been ideated since, tending to facilitate synergies between clients. What a variance with the long hauled Gates' vision of a nascent Microsoft " $a$ computer on every desk at every office and home!"

Future CWS should possess intrinsic augmentative capacity by redeploying space, time and people synergies, concurrently. Where space, time and other resources (capacities, competences, skills, money...) become energy:

\begin{tabular}{c} 
Next Gen CWS \\
$\begin{array}{c}\text { Use and alter space and time conjointly - Enhance and augment local } \\
\text { possibilities - Enhance people and all resources synergies }\end{array}$ \\
\hline
\end{tabular}

Figure 8. A few factors that may lead to conceiving future CWS.

(Schmid, 2012\} says:

"Spaces that have a structure (...) are the modalities according to which design takes account of, and distances itself from, existing objects, so as to create new ones. Whether it is a combinatorial space, where properties can be decoupled, spaces of diffusion allowing the transfer of a property of one discipline into another, or logical and non- 
logical spaces to combine concepts and scientific expertise, these spaces can be described by mathematical structures, topologies, combinatory algebras, algebraic extension. The notion of space or of site is more scientific, even in the effective reality of its practice (the site of the laboratory, the site of the collider, etc.)"

Along this path, a co-working 2.0 concept gets heightened to the status of an ecosystem enabler and may look as a free form space without time limitations, an enabler of synergies among individuals - professionals and not - and formal and informal organizations. In short, a seed engine fostering tomorrow's socio-economies, somewhat in the same way electricity dispatchers fuelled manufacture. For they are founded on knowledge-based thinking.

\section{Departing from current CWS views opens up futures}

Two traditional working modes should be dismissed: meetings and Business Centers. Meetings settings have been so used since the industrial age that they form part of living work styles. However, what's their contribution to CWSs? Don't they bear value when spontaneous (unplanned, ad-hoc, evanescent social gatherings that people form to share feelings and information)? By the coffee corner, participants surprise with different, peculiar ideas, projects and backgrounds unknown to each other. Yet, Business Centers models have existed for decades given they are:

- fixed offices available to guests with some amenities (equipment, stationary...);

- generally stand alone (deprived of service);

- on restricted first come first served access.

Whether CWS enhance freedom and independence, they cut through a worker's isolation and bring useful amenities on-demand.

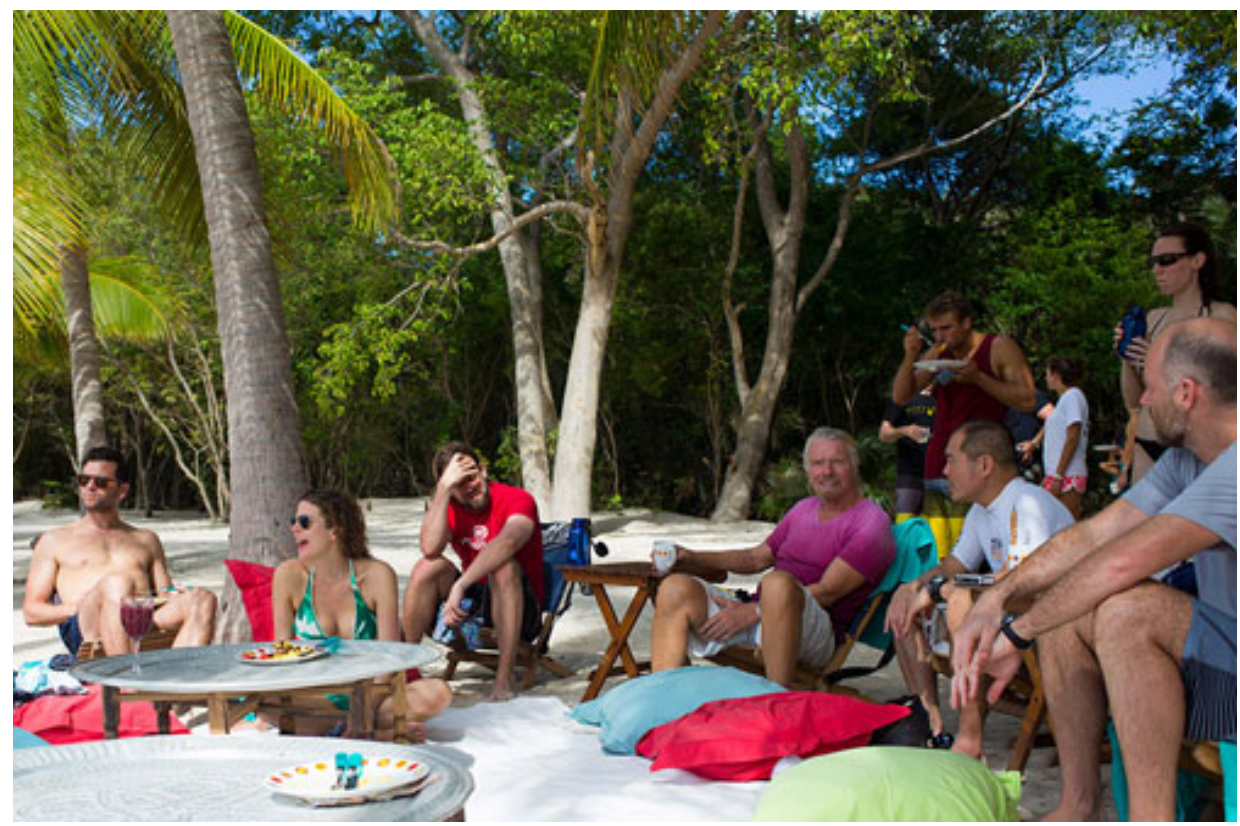

Figure 9. A view of Richard Branson's own CWS style in a Caribbean island ${ }^{5}$ ?

\footnotetext{
${ }^{5}$ Same source as note 8 .
} 


\section{Synthesis: co-working engages ternary mechanisms}

Do key definitional attributes hide behind CWS form factors? Can we design taxonomies for local or temporal adaptation? Figures 10-11 show how flow and movement become the norm in $\mathrm{KS}$.
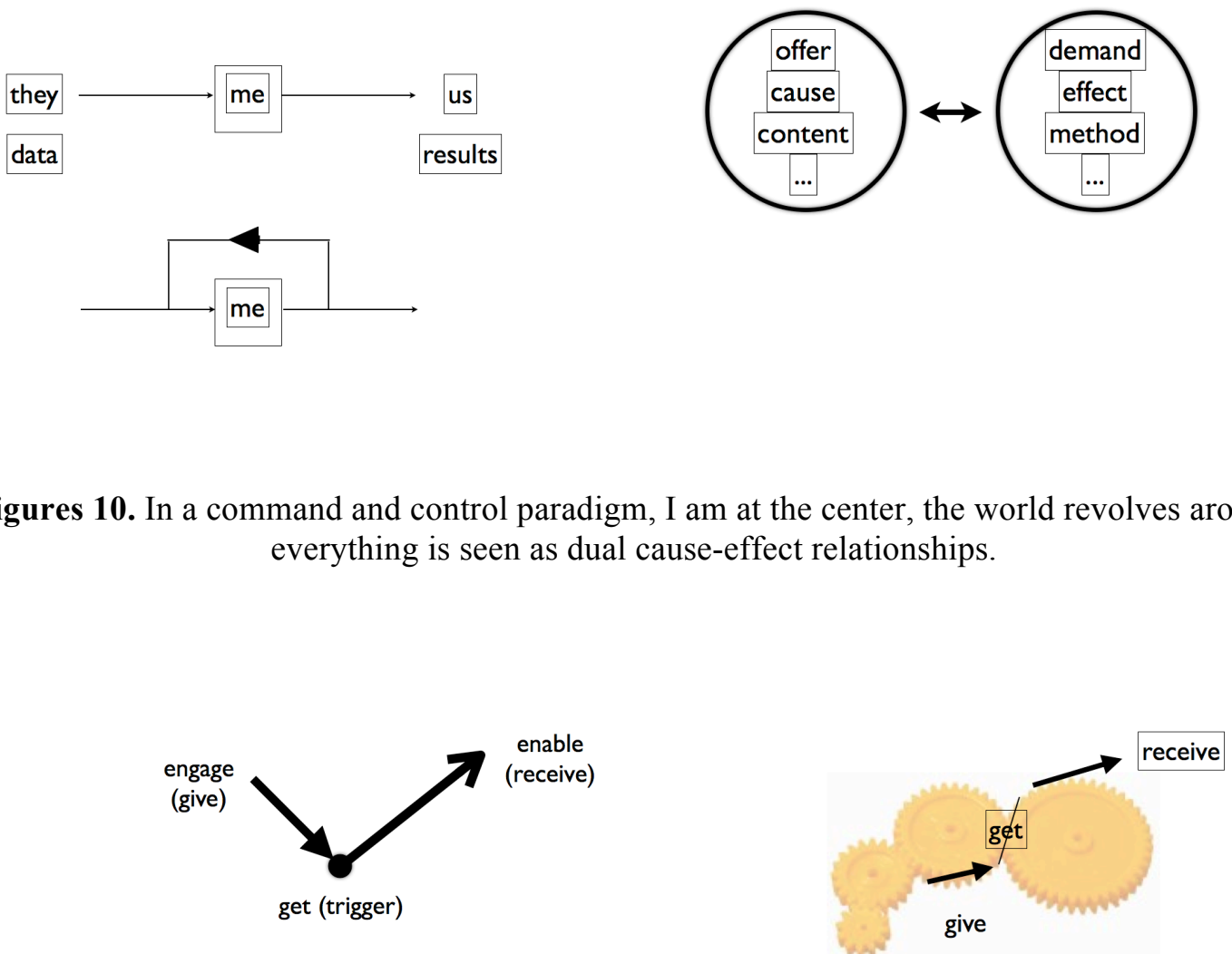

Figures 11. In a post-formal world where knowledge flows, value gets transferred through Get-GiveGear mechanisms each time being transformed by an agent. Ternary logics prevails, yields augmentative growths.

We base 3 Gs ternary systems on three co-articulated notions:

- Giving: transcends but doesn't contradict selling and sharing.

- Getting: exceeds the receiving act and rises above but doesn't contradict buying.

- Gearing: the faculty to put things not in mere rapport but in movement, ever again towards wider operational circles.

A CWS can be envisaged as an experimental laboratory compositing multidisciplinary, multi-sector teams bottom-up. What a rupture with traditional economy thinking. 


\section{PART III - MOBILISING STATE-OF-THE-ART KNOWLEDGE FOR CWS}

Above CWS definitions (Figs. 4, 7, \& 8) contained implicit assumptions: to enhance both the creativity and network readiness of the worker, to host a mix of profiles with different skills. In practice, much of a CWS value may fall outside.

\section{On generating CWS with $\mathrm{C}-\mathrm{K}$ theory}

C-K theory is an axiomatic of design reasoning, capable to account for (detecting, expliciting, tracing) innovation moments, i.e. those locations in progressive conceptual expansions where an innovation potential occurs. This is made possible anytime via expansive partitions that force the breaching of partition spaces, a gapping ability to create breakthroughs revising investigated objects' identities.

The gist is that cognitive fixations are the locks on that path and often remain invisible to the practitioner, hence resist breaking up. "Aha" moments customarily happen when such block are removed (detecting fixations and cognitive debiaising are two process objectives (Corsi, 2013)). Using the C-K formalism was motivated by two requirements:

- a capacity to generate high creativity degrees in designing novel co-working environments,

- easing the management of resulting projects.

\section{Limits to a varied CWS concept}

Today, the CWS concept spans a variety of forms:

Co-working spaces, meeting places, presentation and informal exchanges locations, sharing of experience, animations, experimentation of usages...

Events organization, barcamps, trainings, meetings, press conferences, creativity sessions, new technologies presentations, new concepts experimentations...

Modularity, friendliness and conviviality, relaxing...

Stimulation of entrepreneurial initiatives that resonate with social, environmental, economical, and cultural challenges...

Figure 12. CWS are manifold in features.

Only extensive lists of Innovation hubs (café/tea/theatre/... boutiques, restaurants-café-store, cantines, "innovation boutiques", possibly the Living Labs, etc.) exist and ontological or intensive CWS classifications lack. If innovation is about timing, where's time? How do CWS articulate, warp time to produce effects? Where's the environment? A double intelligence is missing about the ways:

- to organize co-working processes,

- to approach endogenous interactions with exogenous factors.

The limits to the study aren't easy to define. Leading architects may free themselves from common bounds. Figure 13 shows a "surface folded in an endless Möbius band, floors transform into ceilings, inside into outside $\{. .$.$\} A home that has no beginning and no end."$

6 Dutch architect Janjaap Ruijssenaars from Amsterdam's Universe Architecture (http://www.universearchitecture.com/) designed a one-piece building to be built on a giant 3D printer. Can we print a CWS? http://tech.slashdot.org/story/13/01/20/153214/dutch-architect-plans-3d-printedbuilding. 


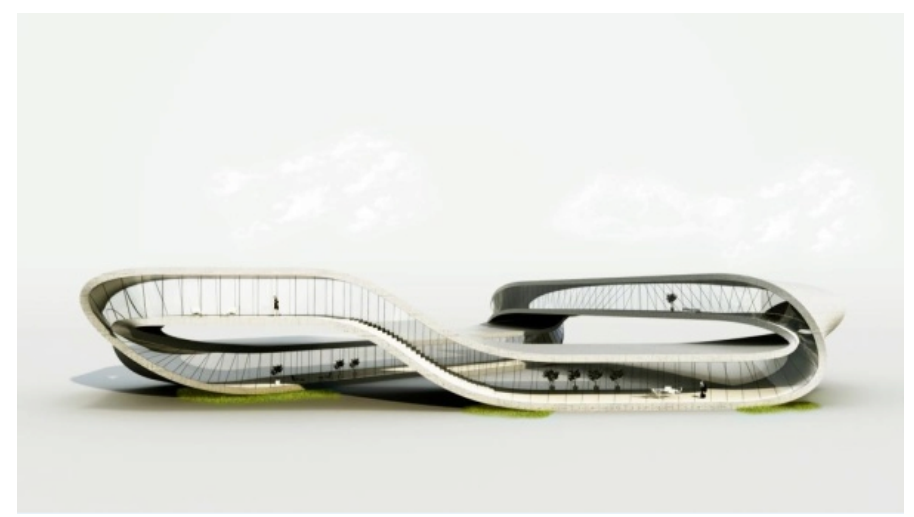

Figure 13. Can this be a CWS?

\section{When KS becomes a... design space}

The first phase when implementing C-K theory is to review the conceptual definition of a CWS and embed it into an ecosystemic understanding of the design activity. Having reformulated the investigation direction (the novel $\mathrm{C} 0$ concept), $\mathrm{K} 0$ being the state-of-theart knowledge on the target thematic, we consider the couple ( $\mathrm{C} 0$, relative-to- $\mathrm{K} 0)$ as the starting point for $\mathrm{C}-\mathrm{K}$ investigation. These questions may help:

- "What are the underpinning factors at play for a CWS?"

- "What are the available pockets of knowledge which exploration may lead to uncover new possibilities?"

- "Which apparent weak signals? What may reveal them and what they tell?"

To structure the relative knowledge acquisition and concepts expansions.

\section{Synthesis of findings}

Our field experiments (Blanchard \& al, 2013, Corsi, 2013) show seven findings:

1. The ecosystem in which CWS operate (explicitly, implicitly) is a main factor.

- Corollary: anything that isolates something or somebody (subsystem?) lessens CWS and relating and socializing are two factors.

- Advancing CWS research is akin to studying ecosystems with system feedback thinking.

2. CWS should operate networking effortless (a given for anybody). Corollary: networking friction (energy dissipation energy) should be minimal.

3. CWS should operate networks rules best:

- Metcalfe's law: the value of a network (ability to connect nodes from any peer to any peer) grows per $1 / 2$ nodes square number.

- Gilder's law ${ }^{7}$ : network bandwidth (the potential for communicating) grows exponentially with time.

Hence, communication capacity growths three times faster than computer power, a CWS deployment driver.

Corollary: in given CWS, concept-ideas flow in rapport to above performance of these laws (synergy level between persons...), measuring CWS performance

\footnotetext{
${ }^{7}$ Innovation is fuelled by "intelligence [that] populates the periphery of networks, i.e. the people who inhabit and use the network".
} 
on qualitative and quantitative ideas flows, transforming Power into Potentiality (Fig. 1) into exponentiality, calling for adaptation instead of control (Corsi, 09).

4. The culture that permeates a CWS polarizes innovation.

- Corollary: CWS will attract people in resonance to their culture, repel others. How to relate with people in dissonance with goals: filter them out? Insert them as rich noise? Profiling CWS is key at design stage.

5. The mutualizing resources that bases CWS should be a multiplying, not divisive factor (e.g. cost: participating expenses a fraction of what it costs to work alone, let alone the faculty to vary work intensity, working relationships and use of the facilities in space and time). Basing relative business models on usage parameters, not buying exclusive usage: mutualizing objects and services.

- Corollary: potential usage intensity is far above individual level. Easy for office equipment, yet when translating the model to non-office objects fully owned by people (car, garage, gardening machines...), it leads to diverging views from today. CWS foster sharing economies having far reaching implications.

- Corollary: full modularity, time and space use range should be accessible, fitting demands from widest arrays.

- Corollary: the looseness of participants' relationship opens up opportunities (full time members, onetime visitors, anything in between, anytime).

6. The displacement factor is key. Should a person come to a CWS or the reverse?

7. Social modalities boundaries (work, play...) blurry: participants lunch together, share news and information...

\section{Summarizing the thinking}

What results from above:

1. CWS should dive into ecosystems.

2. Relating and socializing require system feedback thinking.

3. Variable geometry is a generic design factor encouraging an ability to accelerate exchanges and sustain communication through:

a. effortless participation plus looseness of relationship,

b. mutualizing resources.

By compacting results, we get an evolved origin point for developing $\mathrm{C}-\mathrm{K}$ approaches and reformulate the initial $\mathrm{C} 0$ co-working root concept:

\section{$\mathrm{CO}^{\prime}$}

«An open, free time access environment that is pre-structured to favor the meeting, communication, cooperation, coordination, and collaboration between fortuitous or not persons that favors:

-inventive and surprising individuals' faculties,

-discovery and innovation by individuals and organizations."

Figure 14. A radical CO' concept to start-off $C$ - $K$ processes.

Here's the capacity to create new knowledge from and for CWS stakeholders' space: users, managers, architects, designers, energy suppliers, partners, associations, public authorities, operators... 


\section{PART V - CONCLUSION: CAN ANYTHING REMAIN SAME?}

\section{KS: a phase of evolution?}

The transformational process lucidly foreshadowed by Peter Ducker undergoes an soaring ascent, a new resolving paradigm for economy, society and man where:

- Top-down concentrated powers (monetary, energetic, production...) may leave the way to more bottom-up, distributed dynamics generating emerging options.

- Prediction gets intractable, long-range planning of diminishing value.

- Management by fixed objectives smoothens towards setting conditions for emerging strategies and caring for all resources.

This mutation towards living-by-emergence percolates all socio-economic realms. It's being fueled by three congruent new growth engines:

- Physical and immaterial social/professional networks -maintained competence, trust and confidence openly cement entire operational systems.

- A progressive intertwining of disciplines towards transdisciplinarity -disciplines bound to becoming "dimensions", undergoing inclusion processes.

- An ambient culture of fluidity -exchanging and sharing are two common yet precursor communication models, being subsumed by cooperative, collaborative models.

Alignment with inside-outside axes (people, organizations, firms...) and the embodying of systemic factors become two paramount measures for diagnosing sustainability.

\section{Dual models exiting...}

The transformation results in new positioning roles for transferable assets (intellectual capital, money...). Ternary mechanisms transcend traditional bipolar offer-demand axes by engaging into augmentative capabilities everywhere.

Money is an example, being presently altered into many alternative currency systems ${ }^{8}$. The "dilution" of money as unique carrier medium probably signifies a positioning shift:

Static: buying power compensation $\rightarrow$ Dynamic: transitive augmentation

In KS, you don't need money to strive but an acute capacity to install and sustain augmentative flows. As revolutionary this may seem for many literate professionals, it's simple observation: past wealth was quite often produced from poorest origins, revealing astounding capacities for creating links-and-flows first, not command-and-control.

Today, we can understand, even generalize the processes, with a promise to originate and grow more wealthy societies. A new economy chapter is being written with intangibles as leading drivers (rapport intangible/tangible poised to reverse the image of firms on their markets, also society's reflexive view). If Data and objects were long fixed and locked in silos, Information showed a restless resource, porous and breaching, Knowledge creatively circulates beyond structures, interacts with Knowledge, generating augmentative spirals of becoming that may soon encompass all that can be. A new culture roots creative and competitive humus.

Yet, as knowledge carries content and meaning, it's always vested with ethics. Creativity uniquely drive the powerful incentive represented by intangible assets, of which next

\footnotetext{
${ }^{8}$ above 5000 around the world according to Belgian expert Bernard Liétard.
} 
generation CWS are key components. For the above to become the dominant scenario, more grass root involvement is needed, where ethics is integrated within creative educational and development processes. Should this not be the case, could reverse scenarios that force a continued "business as usual" stance doom society's evolution?

\section{BIBLIOGRAPHY}

Allee V., (2003), The Future of Knowledge: Increasing Prosperity Through Value Networks Butterworth-Heinemann, Elsevier Science.

P., (2009), Towards Quantum Foresight - Founding a Post-Modern Basis for Futures Studies Methodologies, Bulletin of the World Futures Studies Federation, Vol. 34, N³, pp.14-25, July.

Corsi, P. \& Neau, E. (2011) Les dynamiques de l'innovation, modèles, méthodes et outils, Paris, Hermes.

Blanchard. Ph., Corsi P., Christofol H. \& Richir S., (2013), Experimenting C-K Theory in Design-Oriented Educational Context: Analysis of the Process Methodology, Results and Lessons Drawn, $6^{\text {th }}$ SIG Design Theory Paris Workshop of the International Design Society, 4-5 February.

Drucker P., (1995), Post capitalist society. Harper Business, New York, 1993. $2^{\circ}$ edition Butterworth Heinemann.

European Commission, (1994), 'Growth, competitiveness, employment: the challenges and ways forward into the $21^{\text {st }}$ century -White Paper', Office for Official Publications of the European Communities, L 2985 Luxembourg. ISBN 92-826-700-7. (announces the transition towards a new economic logic, leading towards the knowledge society).

Hatchuel, A., \& Weil, B. (2003). A New Approach of Innovative Design: An Introduction to C-K Theory. 14th International Conference on Engineering Design (ICED), 19-21 August, Stockholm.

Hatchuel, A., Le Masson, P. \& Weil, B. (2004), 'C-K Theory in Practice: Lessons from Industrial Applications', International Design Conference - DESIGN 2004, Dubrovnik, The Design Society.

Hatchuel A. \& Weil B., (2007), Design as Forcing: Deepening the Foundations of C-K Theory," International Conference on Engineering Design, 12, Paris.

Le Masson, P., Hatchuel, A. \& Weil, B. (2010), Strategic Management of Innovation and Design, Cambridge: Cambridge University Press.

Luyckx-Ghisi M., La société de la connaissance - Une nouvelle vision de l'économie et du politique, 2008.

Luyckx Ghisi M., (2008), The Knowledge Society: a Breakthrough Towards Genuine Sustainability, Arunchala Press, Cochin, India, www.marcluyckx.eu.

Nonaka I. \& Takeuchi H., (1995), The Knowledge-creating Company: How Japanese Companies Create the Dynamics of Onnovation" Oxford University Press, New York, Oxford.

Rifkin J., (2000), The Age of Access, The New Culture of Hypercapitalism, Penguin, http://www.foet.org/JeremyRifkin.htm.

Rifkin J., (2004), The End of Work, Tarcher Penguin 1995.

Von Neumann J., (1945), First Draft of a Report on the EDVAC.

Acknowledgments

The author thanks Profs. Armand Hatchuel, Benoît Weil and Pascal Le Masson at École des mines de Paris, also Marc Luyckx-Ghisi (ex-Cellule de Prospective member within the European Commission) for their sustained encouragements. 